\title{
Asset Choice And Time Diversification Benefits
}

Amit K. Sinha, (Email: mfsinha@isugw.indstate.edu), Indiana State University Megan Y. Sun, (E-mail: megan.sun@uwrf.edu), University of Wisconsin, River Falls

\begin{abstract}
The issue of time diversification has been controversial. While some findings support time diversification, others do not. For example, Hodges, Taylor and Yoder (1997) find bonds outperform stocks, but Mukherji (2002) finds stocks provide time diversification benefits. This paper investigates whether the differences in the findings of Hodges, Taylor and Yoder (1997) and Mukherji (2002) stem from methodological variation. Results indicate that the differences in the procedure used to estimate the holding period returns may in fact be the reason for the difference in findings. Using a procedure to estimate holding period returns that is similar to Hodges, Taylor and Yoder (1997), and a performance measure that is similar to Mukherji (2002), we do not find that stocks provide time diversification benefits.
\end{abstract}

\section{INTRODUCTION}

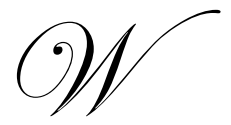

ith over twenty-five trillion dollars ${ }^{1}$ invested in stocks and bonds, the decision to invest in stock or bonds, is perhaps a significant decision an investor has to make. Although, stocks and bonds provide investors with two distinct avenues for investment, the decision to choose one over the other is not as simple as it may appear. For example, although stocks are more risky than bonds in the one period context (Howe and Mistic, 2003), Levy (1978) and Reichenstein (1986), argue that if benefits of time diversification are considered stocks may be better investments than bond. This article investigates this issue further, and specifically attempts to explain the apparently contradictory findings of Hodges, Taylor and Yoder (henceforth HTY) (1997) who find bonds to outperform stocks, and Mukherji (2002) who finds stocks to provide time diversification benefits.

There are two major methodological differences between HTY and Mukherji (2002). While HTY resample historical returns to generate independent returns for longer holding periods, Mukherji (2002) uses rolling overlapping window periods to estimate the holding period returns. HTY use the risk premium per unit of standard deviation ${ }^{2}$ to investigate time diversification benefits, while Mukherji (2002) uses downside risk per unit of return. Thus, answering the question of whether or not the difference in the findings of HTY and Mukherji (2002) is just methodological is the prime objective of this article.

Using monthly returns for stocks and bonds for the period between January 1926 and December 2003, we investigate whether time diversification benefits exist in returns per unit of downside risk using the resampling techniques used by HTY. Results indicate that findings of Mukherji (2002) may just be a methodological issue, as we do not find that stocks dominate bonds, even when downside risk is used to study benefits of holding stocks over long periods of time.

The remainder of this study is organized as follows. In the next session (session 2), we discuss the related literature. In section 3, we describe the data and methodology. In section 4, we present the empirical results. Finally, in section 5 , we conclude the paper with a summary of the evidence.

\footnotetext{
${ }^{1}$ Reilly and Brown (2003) point out that in 2000 US bonds and equities accounted for $43.5 \%$ of the 63.8 trillion dollar world securities market.

${ }^{2}$ Risk premium per unit of standard deviation is the same as the Sharpe Ratio.
} 


\section{LITERATURE REVIEW}

As early as the late seventies, Bernstein (1976) and Lloyd and Haney (1980) are among the first to introduce the concept of "time diversification". They find that the standard deviation of the assets' returns decreases as the holding period lengthens, and argue that time is also an important factor in reducing a portfolio's risk. Lloyd and Modani (1983) reconfirm time diversification by showing that portfolios with larger proportions of common stocks have higher returns and lower risk. Later, McEnally (1985) shows that when risk is measured by standard deviation of the average of annualized returns, risk declines as the horizon lengthens. However, when risk measure is measured by standard deviation of total holding period returns, risk uniformly increases with horizon length. He concludes that time diversification is not the surest route to lower risk. Kritzman (1994) argues that although investors are less likely to lose money over a long horizon than over a short one, the magnitude of one's potential loss increases with the duration of the investment horizon. However, he points out that though time does not diversify risk, there are several reasons why investors might still condition their risk exposure on their time horizon.

Ever since then, the concept of "time diversification" has been studied and challenged both theoretically and empirically. With a few exceptions, theorists mostly argue that, given serially uncorrelated returns, holding a risky asset over longer periods of time will not reduce its inherent riskiness. This argument is supported by references to economic models of risk aversion, such as mean-variance optimization, expected utility theory, option pricing theory, etc.

The option-based approach is initiated by Bodie (1995), where risk is defined as the cost of insurance against earning less than the risk free rate over the holding period. Bodie criticizes time diversification as a fallacy in his 1995 paper. Following this option pricing approach, Merrill and Thorley (1996), however, provide evidence that longer time horizons reduce the risk of equity investments by analyzing financially engineered securities that guarantee a minimum return. They find that when risk is measured by the fair cost of insuring a minimum return, it is lower for longer horizons. Zou (1997) argues that risk as measured by the cost of insuring a minimum rate of return is not a monotonic function of the portfolio's time horizon. He concludes that there is no uniform answer to the issue of time diversification. In a response to Merrill and Thorley (1996), Oldenkamp and Vorst (1997) attack the effectiveness of using an option-pricing model to identify a time diversification benefit. Rather, they simulate the probability distribution of returns and find that investments with a longer time horizon have higher standard deviations, though with higher expected returns. Hence, equity investments are not necessarily safer for longer time horizons than for short time horizons.

Besides the option based approach, some other theorists resort to utility function maximization to challenge the time diversification concept. Milevsky (1999) uses optimization theory to maximize a Safety-First (downside risk-aversion) utility function and asserts that investors with the above utility function are invariant to the time horizon and also asserts that longer time horizons do not reduce risks. Hansson and Persson (2000) use a nonparametric bootstrap approach on a mean-variance-efficient portfolio framework. They find that the weights for stocks in an efficient portfolio are significantly larger for long investment horizons than for a one-year horizon and that an investor can gain from time diversification. Using both US and UK data, Strong and Taylor (2001) also lend their support to time diversification using a mean-variance utility function optimization. Gollier (2002) proposes to apply a new theoretical model to the notion of time diversification. He shows that time diversification occurs when investors have no liquidity constraint, while the existence of liquidity constraints reduces the time diversification benefit.

While theorists apply different models to test time diversification, empirical studies on this issue mainly focus on resampling historical data. Empirical tests on time diversification involve calculating returns and risks in longer time horizons, but given the short history of the financial market, these tests are weakened by a shortage of independent return observations. However, by assuming that past stock and bond market performance repeats itself, thousands (even millions) of independent observations can be obtained by resampling the observed distribution of asset returns ${ }^{3}$. For example, based on annual returns from 1926 to 1993 , HTY resample the return distribution and

\footnotetext{
${ }^{3}$ More important, it does not require making distribution assumptions of asset returns.
} 
yield a large number of independent holding returns for a period from 1 year to 30 years. HTY then use the Sharpe Ratio to evaluate performance and find that stocks do not provide time diversification benefits.

Mukherji (2002) introduces downside risk while investigating time diversification. Mukherji (2002) investigates downside risk by estimating the coefficient of downside risk, which he estimates by dividing the downside deviation by the mean value of returns. When downside risk is used as the risk measure, stocks dominate bonds over the long horizon, and investors are better off investing in stocks to achieve time diversification benefits. However, Mukherji (2002) uses rolling overlapping window periods to estimate the holding period returns. The question remains whether time diversification benefits exist if an alternate method, like resampling, is used to obtain a time series of holding period returns.

Thus the two major differences between HTY and Mukherji (2002) are: (i) the technique used to estimate holding period returns ${ }^{4}$, and (ii) the measures used to evaluate performance. The question arises whether the findings of Mukherji (2002) change if one uses a measure similar to that used by Mukherji (2002), while using the technique used by HTY to estimate holding period returns.

\section{DATA AND METHODOLOGY}

The data consisting of monthly returns for small and large stocks, long term corporate and long term government bonds, and treasury bills was obtained from Ibbotson Associates (2004) for the period from January 1926 to December 2003.

\section{Resampling Methodology}

The resampling procedure adopted in this study is similar to HTY. Similar to HTY and Mukherji (2002), we study small stocks, large stocks, long-term corporate bonds, and long-term government bonds. The holding period return is estimated using the following three step procedure:

Step 1: For a given holding period of $n$ years, $n \times 12$ returns are randomly selected from 936 historical monthly returns.

Step 2: $n$-year holding period return is generated by using the following formula:

$$
H P R_{n}=\prod_{i=1}^{n \times 12}\left(1+R_{i}\right)-1
$$

where $H P R_{n}=n$-year holding period return

$R_{i}=$ monthly return observations for period I

$n=$ number of years in the holding period

The holding period return differs from HTY and Mukherji (2002) who use $\operatorname{HPR}_{n}=\prod_{i=1}^{n}\left(1+R_{i}\right)$. Our measure is a proper representation of the holding period return, while their measures are a proper representation of the future wealth at the end of the holding period.

\footnotetext{
${ }^{4}$ Mukherji (2002) does not employ the resampling technique. He generates returns based on rolling overlapping holding periods. According to Howe and Mistic (2003), due to the overlapping, the returns generated by Mukherji (2002) are no longer independent, which casts doubt upon his final conclusions.
} 
Step 3: For each holding period, ranging from 1 to 30 years, this process is repeated 5,000 times resulting in 5,000 holding period returns for each horizon.

\section{Risk Measure and Performance Measure}

Another issue raised by time diversification studies is the choice of risk measure and corresponding performance measure. HTY use the standard deviation as the risk measure and Sharpe ratio (Sharpe 1966, 1994) as the performance measure.

The Sharpe ratio is estimated as follows:

$S_{p}=\frac{\bar{R}_{p}-\bar{R}_{f}}{\sigma_{p}}$

where $S_{p}=$ Sharpe ratio of the portfolio for the holding period

$\overline{\mathrm{R}}_{\mathrm{p}}=$ average holding period return of the portfolio for each horizon

$\overline{\mathrm{R}}_{\mathrm{f}}=$ risk-free holding period return for each horizon

$\sigma_{\mathrm{p}}=$ standard deviation of holding period returns

In Sharpe ratio, standard deviation of returns is used as the risk measure. However, as the investment horizon lengthens, it is not clear if standard deviation is the best measure of risk. Olsen (1997) shows that CFA (Chartered Financial Analysts) charter holders rank the potential of obtaining below target returns as the greatest investment risk. Hence, downside deviation rather than standard deviation should be used in order to measure downside risk. Downside deviation is calculated as the lower partial variance of returns as in Mukherji (2002) and Howe and Mistic (2003). Correspondingly, a performance measure that considers potential for below target returns might be better suited to evaluate the performance of long horizon returns. The Sortino ratio is one such measure (Sortino and Lee, 1994).

The Sortino ratio is reward-to-risk measure based on a minimum acceptable rate of return (MAR) for an individual investor, and is scaled by the downside risk, instead of total risk as is the case with the Sharpe ratio. The Sortino ratio is estimated by:

Sortino Ratio $=\frac{\left(\mathrm{HPR}-\mathrm{R}_{\mathrm{MAR}}\right)}{\mathrm{DD}_{\mathrm{MAR}}}$

where HPR = holding period returns

$\mathrm{R}_{\mathrm{MAR}}=$ minimum acceptable returns (target returns) for the holding period

$\mathrm{DD}_{\mathrm{MAR}}=$ the downside deviation and is measured as lower partial variance, a traditional semi-variance measure:

$\mathrm{DD}_{\mathrm{MAR}}=\left(\frac{\left(\sum_{i=1}^{\mathrm{N}}\left(\mathrm{L}_{\mathrm{i}}\right)^{2}\right)}{\mathrm{N}}\right)^{1 / 2}$ 
where $L_{i}=R_{i}-R_{M A R}\left(\right.$ If $\left.R_{i}-R_{M A R}<0\right)$ or 0 (If $R_{i}-R_{M A R}>0$ ).

$\mathrm{N}=$ number of periods

$\mathrm{R}_{\mathrm{i}}=$ return for period $\mathrm{i}$.

The Sortino ratio is in fact the reciprocal of the coefficient of downside risk, as defined and used by Mukherji (2002). The coefficient of downside deviation is obtained by dividing the downside deviation by the mean value of excess returns, indicating the downside risk per unit of return. A greater value indicates a higher risk of yielding below target return per unit of return.

$$
\text { Coefficient of Downside Deviation }=\frac{1}{\text { Sortino }}=\frac{D_{M A R}}{H P R-R_{M A R}}
$$

This study uses downside risk as the risk measure and Sortino ratio as the performance measure, rather than using the coefficient of downside deviation.

\section{Risk on Holding Period Returns}

As demonstrated by Kochman and Goodwin $(2001,2002)$, there are two ways to calculate the standard deviation of returns in longer horizons. The first approach is to calculate the standard deviation of the average of annual returns during the overall holding period, while the second is to calculate the standard deviation of total holding period returns. Past research shows that when the first approach is used, standard deviation (risk) is a decreasing function of time, while when the second approach is used, risk increases over time. HTY point out that the reward to risk performance measure is valid only if the intended investment horizon is equal to the holding period of returns used to compute the ratio. This study therefore calculates the risk using total holding period returns rather than the average of annual returns during the holding period as in Mukherji (2002).

\section{EMPIRICAL RESULTS}

Table I presents the mean holding period returns of all four types of assets over various holding horizons. The table reveals that in all cases, the mean holding period return increases as the holding period lengthens. The mean return for small stocks increases from $12.6 \%$ for a 1 -year holding period to $13,319 \%$ for a 30 -year holding period. The corresponding mean returns for large stocks are $12.3 \%$ and 3,447\% for a 1-year and 30-year holding horizon. The mean returns for long-term corporate bonds are $6.3 \%$ and $498 \%$ respectively and for long-term government bonds are $5.7 \%$ and $421 \%$ respectively for a 1-year and 30-year holding period. Small stocks have the highest average holding period return, and long-term government bonds have the lowest average holding period return, with large stocks and long-term corporate bonds ranking second and third in between. 
Table I: Means for Portfolios of Small Stocks, Large Stocks, Long-Term Corporate Bonds, and Long-Term Government Bonds

\begin{tabular}{|c|c|c|c|c|}
\hline $\begin{array}{c}\text { Holding Period } \\
\text { (Years) }\end{array}$ & Small Stocks & Large Stocks & Corporate Bonds & Government Bonds \\
\hline 1 & 0.179 & 0.123 & 0.063 & 0.057 \\
\hline 2 & 0.392 & 0.275 & 0.124 & 0.105 \\
\hline 3 & 0.610 & 0.434 & 0.191 & 0.181 \\
\hline 4 & 0.872 & 0.593 & 0.271 & 0.243 \\
\hline 5 & 1.247 & 0.811 & 0.341 & 0.315 \\
\hline 6 & 1.554 & 1.028 & 0.435 & 0.391 \\
\hline 7 & 2.068 & 1.233 & 0.506 & 0.504 \\
\hline 8 & 2.402 & 1.612 & 0.620 & 0.569 \\
\hline 9 & 3.127 & 1.857 & 0.708 & 0.649 \\
\hline 10 & 3.998 & 2.178 & 0.804 & 0.744 \\
\hline 11 & 5.007 & 2.868 & 0.940 & 0.865 \\
\hline 12 & 6.148 & 3.096 & 1.032 & 0.961 \\
\hline 13 & 7.784 & 3.687 & 1.173 & 1.046 \\
\hline 14 & 9.005 & 4.225 & 1.315 & 1.191 \\
\hline 15 & 10.476 & 5.071 & 1.436 & 1.312 \\
\hline 16 & 11.194 & 5.648 & 1.607 & 1.394 \\
\hline 17 & 14.976 & 6.212 & 1.768 & 1.607 \\
\hline 18 & 16.597 & 7.533 & 1.903 & 1.716 \\
\hline 19 & 21.139 & 9.021 & 2.043 & 1.820 \\
\hline 20 & 24.130 & 9.372 & 2.312 & 2.048 \\
\hline 21 & 31.968 & 10.902 & 2.480 & 2.228 \\
\hline 22 & 33.516 & 11.990 & 2.739 & 2.429 \\
\hline 23 & 41.341 & 13.974 & 2.881 & 2.638 \\
\hline 24 & 39.285 & 16.000 & 3.203 & 2.734 \\
\hline 25 & 52.612 & 17.634 & 3.471 & 2.983 \\
\hline 26 & 57.375 & 19.947 & 3.669 & 3.308 \\
\hline 27 & 72.225 & 21.897 & 4.027 & 3.568 \\
\hline 28 & 120.241 & 27.809 & 4.285 & 3.768 \\
\hline 29 & 94.205 & 30.961 & 4.600 & 3.987 \\
\hline 30 & 133.319 & 34.471 & 4.988 & 4.206 \\
\hline
\end{tabular}

As average holding period return increases with the length of the horizon, total risk -- as measured by the standard deviation of the total holding period return -- also increases with the length of the holding period, as seen in Table II. For a 1-year and 30-year holding period, the standard deviation for small stocks grows from $33.5 \%$ to $44,984 \%$. The corresponding standard deviations of corporate bonds are $7.6 \%$ and $226 \%$ respectively. When ranking the standard deviation of holding period returns across assets, small stocks rank first, large stocks score second and corporate bonds score third. Long-term government bonds rank last on the list. Combining Tables I and II, we find that while small stocks have the greatest holding period returns, they also have the greatest volatility 
Table II: Total Risk (Standard Deviation) for Portfolios of Small Stocks, Large Stocks, Long-Term Corporate Bonds, And Long-Term Government Bonds

\begin{tabular}{|c|c|c|c|c|}
\hline $\begin{array}{l}\text { Holding Period } \\
\text { (Years) }\end{array}$ & Small Stocks & Large Stocks & Corporate Bonds & Government Bonds \\
\hline 1 & 0.335 & 0.222 & 0.076 & 0.081 \\
\hline 2 & 0.596 & 0.354 & 0.112 & 0.116 \\
\hline 3 & 0.846 & 0.473 & 0.140 & 0.170 \\
\hline 4 & 1.090 & 0.661 & 0.172 & 0.196 \\
\hline 5 & 1.721 & 0.825 & 0.206 & 0.233 \\
\hline 6 & 2.001 & 1.039 & 0.230 & 0.270 \\
\hline 7 & 2.769 & 1.196 & 0.277 & 0.325 \\
\hline 8 & 3.042 & 1.567 & 0.316 & 0.361 \\
\hline 9 & 4.892 & 1.722 & 0.368 & 0.401 \\
\hline 10 & 7.223 & 1.983 & 0.402 & 0.424 \\
\hline 11 & 7.753 & 2.899 & 0.453 & 0.502 \\
\hline 12 & 8.527 & 3.230 & 0.485 & 0.560 \\
\hline 13 & 12.687 & 4.022 & 0.551 & 0.606 \\
\hline 14 & 13.100 & 4.458 & 0.625 & 0.687 \\
\hline 15 & 17.455 & 5.914 & 0.668 & 0.732 \\
\hline 16 & 22.417 & 6.523 & 0.740 & 0.754 \\
\hline 17 & 36.633 & 6.515 & 0.815 & 0.858 \\
\hline 18 & 28.747 & 8.466 & 0.878 & 0.942 \\
\hline 19 & 47.823 & 13.979 & 0.921 & 0.964 \\
\hline 20 & 47.552 & 11.137 & 1.051 & 1.078 \\
\hline 21 & 109.061 & 13.067 & 1.096 & 1.197 \\
\hline 22 & 80.364 & 13.797 & 1.232 & 1.307 \\
\hline 23 & 127.520 & 17.197 & 1.286 & 1.476 \\
\hline 24 & 78.078 & 22.122 & 1.521 & 1.504 \\
\hline 25 & 114.879 & 26.937 & 1.592 & 1.651 \\
\hline 26 & 145.972 & 26.199 & 1.719 & 1.752 \\
\hline 27 & 144.428 & 28.223 & 1.798 & 1.854 \\
\hline 28 & 902.100 & 40.717 & 2.003 & 2.102 \\
\hline 29 & 210.453 & 60.245 & 2.186 & 2.202 \\
\hline 30 & 449.842 & 51.002 & 2.266 & 2.204 \\
\hline
\end{tabular}

As mentioned above, the greatest concern for investors in investing on a long-term basis is not the risk of volatility but the risk of obtaining lower than target returns. Following Mukherji (2002) and Howe and Mistic (2003), we further explore the pattern of the downside risk measured by the risk of yielding below target returns. Using returns on T-bills as the target, we report the downside risk in Table III and graph the results in Figure 1. Table III shows that the downside risk for each portfolio increases as the holding period is lengthened. The downside risks for small stocks is $12.6 \%$ for a 1-year holding period, and increases to $34.6 \%$ for a 30 -year holding period. Correspondingly, the downside risks for large stocks are $9.8 \%$ and $24.9 \%$ respectively for a 1 -year and 30-year holding period. The downside risks for long-term corporate bonds are much smaller, estimated at $3.5 \%$ and $10.7 \%$ respectively for a 1-year and 30-year holding period. Interestingly, the downside risk for long-term government bonds is higher than that of long-term corporate bonds. As the time horizon increases, the downside risk for long-term government bonds becomes closer or at times, higher than the downside risk of large stocks. Ranking the downside risk across assets, we find that small stocks have the greatest downside risk and hence the greatest possibility of yielding a return lower than T-bills. Large stocks rank second in terms of downside risk among the four types of assets. Long-term government bonds rank third, while long-term corporate bonds have the lowest downside risk. 
Table III: Downside Risk (Downside Deviation) for Portfolios of Small Stocks, Large Stocks, Long-Term Corporate Bonds, and Long-Term Government Bonds

\begin{tabular}{ccccc}
\hline $\begin{array}{c}\text { Holding Period } \\
\text { (Years) }\end{array}$ & Small Stocks & Large Stocks & Corporate Bonds & Government Bonds \\
\hline 1 & 0.126 & 0.098 & 0.035 & 0.044 \\
2 & 0.164 & 0.115 & 0.051 & 0.063 \\
3 & 0.192 & 0.121 & 0.055 & 0.075 \\
4 & 0.207 & 0.143 & 0.061 & 0.081 \\
5 & 0.204 & 0.158 & 0.067 & 0.091 \\
6 & 0.223 & 0.163 & 0.064 & 0.094 \\
7 & 0.230 & 0.169 & 0.073 & 0.097 \\
8 & 0.217 & 0.154 & 0.078 & 0.105 \\
9 & 0.266 & 0.189 & 0.084 & 0.120 \\
10 & 0.249 & 0.189 & 0.083 & 0.125 \\
11 & 0.276 & 0.185 & 0.083 & 0.149 \\
12 & 0.226 & 0.182 & 0.086 & 0.154 \\
13 & 0.254 & 0.187 & 0.091 & 0.148 \\
14 & 0.283 & 0.197 & 0.097 & 0.150 \\
15 & 0.284 & 0.181 & 0.100 & 0.164 \\
16 & 0.321 & 0.203 & 0.098 & 0.155 \\
17 & 0.298 & 0.200 & 0.112 & 0.163 \\
18 & 0.304 & 0.175 & 0.094 & 0.182 \\
19 & 0.311 & 0.205 & 0.097 & 0.178 \\
20 & 0.261 & 0.219 & 0.112 & 0.188 \\
21 & 0.303 & 0.196 & 0.110 & 0.193 \\
22 & 0.325 & 0.197 & 0.101 & 0.184 \\
23 & 0.265 & 0.200 & 0.119 & 0.229 \\
24 & 0.360 & 0.234 & 0.129 & 0.209 \\
25 & 0.376 & 0.221 & 0.129 & 0.193 \\
26 & 0.330 & 0.180 & 0.132 & 0.213 \\
27 & 0.368 & 0.242 & 0.141 & 0.236 \\
28 & 0.363 & 0.257 & 0.125 & 0.238 \\
29 & 0.318 & 0.192 & 0.121 & 0.265 \\
30 & 0.346 & 0.249 & 0.108 & \\
\hline
\end{tabular}




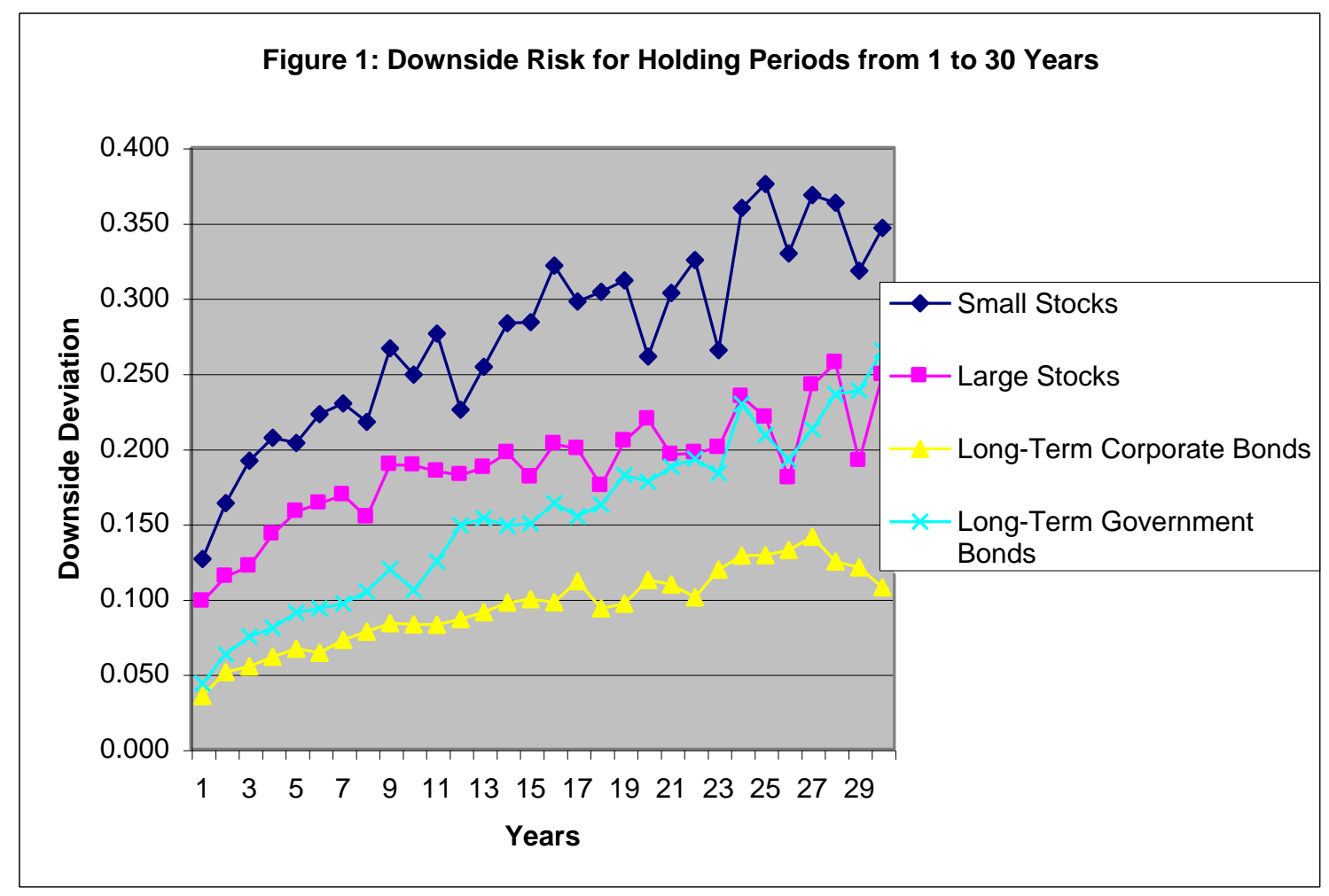

Our finding regarding the downside risk contradicts that of Mukherji (2002) who claims that the downside risk decreases as holding period lengthens and downside risk for stocks is lower than that for bonds. Since Mukherji (2002) generates holding period returns by rolling overlapping holding periods, a methodology that has not generated independent returns, his conclusions are no longer reliable. Therefore, according to the findings in this study, stocks have a greater risk of yielding below target returns and hence there is no evidence of time diversification of stocks over bonds.

Table IV presents the reward-to-downside-risk ratios (Sortino ratio) for all four assets and Figure 2 graphs the ratio. The Sortino ratio increases as the holding period extends. The Sortino ratio for small stocks starts at 1.12 for a 1-year holding period and finishes at 378.99 for a 30-year holding period. Similarly, for the 1-year and 30-year holding period, the Sortino ratio for large stocks grows from 0.87 to 130.45 . The magnitude of change of Sortino ratio for long-term corporate bonds and long-term government bonds for a 1-year and 30-year holding period are not as dramatic as those for small stocks and large stocks. The Sortino ratio for long-term corporate bonds increases from 0.73 to 27.67, while the Sortino ratio for long-term government bonds grows from 0.45 to 8.27 from a 1 -year to 30year holding period. Comparing the Sortino ratios at different holding horizons across all four types of assets, we find that small stocks have the highest Sortino ratio, while long-term government bonds have the lowest Sortino ratio. In other words, the compensation for bearing one unit of downside risk is greatest for small stocks and least for longterm government bonds, with large stocks and long-term corporate bonds ranking in between. Since Sortino ratio is essentially the reciprocal of the coefficient of downside risk as defined by Mukherji (2002), our finding here on Sortino ratio is in fact consistent with the finding of Mukherji (2002) on coefficient of downside risk.

Overall, this study documents that even though the holding period return is higher for stocks than for bonds, the downside risk for stocks is also higher than for bonds. Therefore, even though on a return per unit downside risk basis, stocks seem to be a better investment than bonds in the long run, there is no evidence that stocks dominate 
bonds in the return-downside risk plane. The empirical evidence presented here doesn't lend support to time diversification. On the contrary, it claims that time diversification does not exist.

Table IV: Sortino Ratio (Reward-to-Downside-Risk) for Portfolios of Small Stocks, Large Stocks, Long-Term Corporate Bonds, and Long-Term Government Bonds

\begin{tabular}{ccccc}
\hline $\begin{array}{c}\text { Holding Period } \\
\text { (Years) }\end{array}$ & Small Stocks & Large Stocks & Corporate Bonds & Government Bonds \\
\hline 1 & 1.122 & 0.875 & 0.732 & 0.454 \\
2 & 1.931 & 1.737 & 0.921 & 0.460 \\
3 & 2.572 & 2.609 & 1.345 & 0.856 \\
4 & 3.445 & 3.041 & 1.826 & 1.048 \\
5 & 5.130 & 3.858 & 2.071 & 1.243 \\
6 & 5.873 & 4.790 & 2.943 & 1.544 \\
7 & 7.729 & 5.570 & 2.939 & 2.185 \\
8 & 9.476 & 8.231 & 3.557 & 2.169 \\
9 & 10.260 & 7.742 & 3.751 & 2.135 \\
10 & 14.266 & 9.185 & 4.311 & 2.820 \\
11 & 16.309 & 12.822 & 5.321 & 2.923 \\
12 & 24.781 & 13.940 & 5.506 & 2.722 \\
13 & 28.224 & 16.444 & 6.164 & 2.828 \\
14 & 29.434 & 18.023 & 6.568 & 3.477 \\
15 & 34.320 & 23.974 & 7.016 & 3.827 \\
16 & 32.320 & 23.882 & 8.217 & 3.603 \\
17 & 47.396 & 26.767 & 8.068 & 4.783 \\
18 & 51.517 & 37.638 & 10.277 & 4.769 \\
19 & 64.631 & 39.119 & 10.685 & 5.457 \\
20 & 88.322 & 37.768 & 10.900 & 5.650 \\
21 & 101.574 & 49.724 & 11.968 & 6.110 \\
22 & 99.238 & 54.561 & 14.761 & 7.130 \\
23 & 150.896 & 63.090 & 13.013 & 5.732 \\
24 & 105.239 & 62.271 & 13.859 & 7.027 \\
25 & 136.004 & 73.054 & 15.151 & 8.853 \\
26 & 169.205 & 101.840 & 15.609 & 8.762 \\
27 & 191.409 & 83.523 & 16.456 & 8.313 \\
28 & 326.159 & 101.255 & 19.856 & 8.725 \\
29 & 290.182 & 151.654 & 22.282 & 8.278 \\
30 & 378.989 & 130.447 & 27.671 &
\end{tabular}




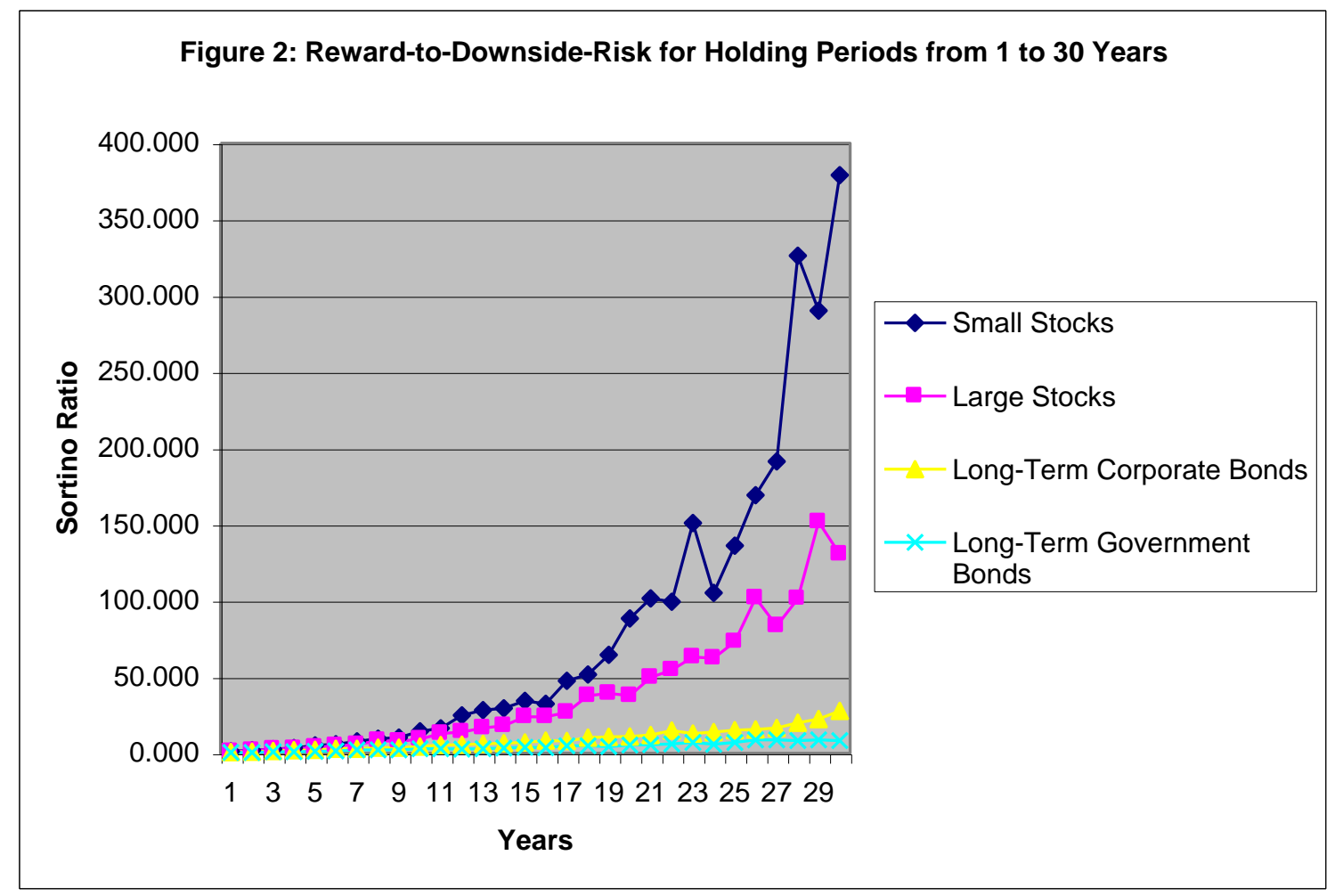

\section{CONCLUSION}

Recent discussions of time diversification have been surrounded by controversy. While HTY do not find time diversification to exist, Mukherji (2002) finds that investors may achieve time diversification by holding stocks. This study thus attempts to reconcile the differences between HTY and Mukherji (2002). Results indicate that the procedure used to estimate holding period returns and risk makes a big difference in the results of the study. For example, Mukherji (2002) uses downside risk and a rolling window approach to estimate returns, while HTY use the Sharpe Ratio and resampling to obtain independent holding period returns for long holding periods. In this paper, we use downside risk and resampling to investigate whether the results confirm Mukherji (2002) or HTY.

This study documents that small stocks have the greatest downside risk among the four asset types, with large stocks ranking second, long term corporate bonds ranking third, and long term government bonds ranking last. However, the reward-to-downside-risk (the Sortino ratio) ranks greatest for small stocks, second for large stocks, third for long-term corporate bonds, and lowest for long-term government bonds. Even though small stocks have the highest reward-to-downside risk ratio (Sortino ratio), they have greatest risks of missing the target returns, a finding contradictory to Mukherji (2002). This paper finds no evidence of dominance of stocks over bonds in longer holding horizons. Stocks are not necessarily safer and better investments than bonds over longer investment horizons.

\section{REFERENCES:}

1. Bernstein, Peter, 1976, “The time of your life," Journal of Portfolio Management 2, (No. 4, Summer): pp.410.

2. Bodie, Zvi., 1995, “On the Risk of Stocks in the Long Run,” Financial Analysts Journal 51, (No. 3, May/June): pp. 18-22. 
3. Gollier, Christian, 2002, "Time diversification, liquidity constraints, and decreasing aversion to risk on wealth," Journal of Monetary Economics 49, (No. 7, Oct): pp. 1439- 1459.

4. Hansson, Bjorn and Mattias Persson, 2000, "Time diversification and estimation risk," Financial Analysts Journal 56, (No. 5, Sep/Oct): pp. 55-63.

5. Hodges, Charles W., Taylor, Walton R. L., and James A. Yoder, 1997, "Stocks, Bonds, the Sharpe Ratio, and the Investment Horizon," Financial Analysts Journal 53. (No. 6, November/December): 74-80.

6. Ibbotson Associates, 2004, SBBI 2004 Yearbook. Chicago: Ibbotson Associates.

7. Kochman, Ladd, and Randy Goodwin, 2002, "Time diversification: tool, fallacy or both," American Business Review 20, (No. 2, June): pp. 55-57.

8. Kochman, Ladd, and Randy Goodwin, 2001, "Updating the case against time diversification: a note," The Mid-Atlantic Journal of Business 37, (No. 2/3, June/Sep): pp. 139-142.

9. Kritzman, Mark P., 1994, "What practitioners need to know about higher moments," Financial Analysts Journal 50, (No. 5, September/October): pp. 10-17.

10. Levy, Robert A., 1978, "Stock, Bonds, Bills and Inflation over 52 years," Journal of Portfolio Management 4, (No. 4, ) pp 18-19

11. Lloyd, William P., and Richard L. Haney, 1980, “Time diversification: surest route to lower risk," Journal of Portfolio Management 6, (No. 3, Spring): pp. 5-9.

12. Lloyd, William P., and Naval K. Modani, 1983, "Stocks, bonds, bills, and time diversification," Journal of Portfolio Management 9, (No. 3, Spring): pp. 7-11.

13. McEnally, Richard W., 1985, "Time diversification: surest route to lower risk?" Journal of Portfolio Management 11, (No.4, Summer): pp. 24-26.

14. Merrill, Craig and Steven Thorley, 1996, "Time diversification: perspectives from option pricing theory," Financial Analysts Journal 52, (No. 3, May/June): pp. 13-20.

15. Milevsky, Moshe Arye, 1999, "Time diversification, safety-first and risk," Review of Quantitative Finance and Accounting 12, (No.3, May): pp. 271-281.

16. Mukherji, Sandip, 2002, "Stocks, bonds, bills, wealth, and time diversification," Journal of Investing 11, (No.2, Summer): pp. 39-52.

17. Oldenkamp, Bart, and Ton Vorst, 1997, "Time diversification and option pricing theory: another perspective," Journal of Portfolio Management 23, (No.4, Summer): pp. 56-61.

18. Olsen, Robert A., 1997, "Investment risk: the experts' perspective," Financial Analysts Journal 53, (No. 2, March/April): pp. 62-66.

19. Reichenstein, William, 1986, "When Treasury Bills are Riskier than Common Stock," Financial Analyst Journal 42 (No. 6, ): pp. 65-72

20. Reilly, Frank K., Brown, Keith C., 2003, "Investment Analysis and Portfolio Management," $7^{\text {th }}$ edition, Thomson South-Western, ISBN 0-324-17173-0

21. Sharpe, William F., 1966, "Mutual Fund Performance," Journal of Business 39, (No 1, January): pp. 119138.

22. Sharpe, William F., 1994, “The Sharpe Ratio," Journal of Portfolio Management 21, (No. 1, Fall): pp. 49-58.

23. Sinha, Amit K., Sun, Megan Y., 2005 "Stocks, bonds, bills, wealth, and time diversification: Another Review," Working Paper

24. Sortino, Frank A., and N. Price Lee, 1994, "Performance Measure in a Downside Risk Framework," Journal of Investing 3, (No. 3, Fall): pp. 59-64.

25. Strong, Norman and Nicholas Taylor, 2001, "Time diversification: empirical tests," Journal of Business Finance \& Accounting 28, (No. 3/4, Apr/May): pp. 263-303.

26. Zou, Liang, 1997, "Investment with downside insurance and the issue of time diversification," Financial Analysts Journal 53, (No. 4, July/Aug): pp. 73-80. 